\title{
R21 - AVAliaÇÃo dOS Riscos ASSOCIAdOS AO PROCESSO DE OBTENÇÃO DA PARTÍCULA CALIBRADORA E CONTROLE POSITIVO DO KIT NAT HIV/HCV DE BIO-MANGUINHOS
}

Dênis Millan Mendonça ${ }^{1}$, Elezer Monte Blanco Lemes ${ }^{2}$.

1. Bio-Manguinhos, Fundação Oswaldo Cruz, Departamento de Garantia da Qualidade, Rio de Janeiro, Brasil.

2. Bio-Manguinhos, Fundação Oswaldo Cruz, Vice-Diretoria de Produção, Rio de Janeiro, Brasil.

Objetivo: Este trabalho identifica e avalia os riscos do processo produtivo de obtenção da partícula calibradora (PC) e controle positivo (CP), dois importantes insumos do KIT NAT HIV/HCV de Bio-Manguinhos.

Metodologia: Os riscos identificados referem-se ao processo produtivo visando à qualidade dos insumos (PC e CP). Foram utilizadas de forma complementar duas ferramentas de análise de risco: PHA - Preliminary Hazard Analisys (Análise Preliminar de Perigos) e HACCP- Hazard Analysis and Critical Control Points (Análise de Perigos e Pontos Críticos de Controle). A PHA foi utilizada em um primeiro momento para, a partir do fluxograma do processo produtivo, identificar eventos que possam influenciar negativamente a qualidade dos produtos. Estes eventos foram classificados em uma matriz de risco. Delimitamos na matriz de risco uma região associada aos riscos mais importantes. As etapas do processo produtivo onde encontramos os riscos mais importantes foram consideradas Pontos Críticos do Processo (PCC). Os PCC foram estudados mais detalhadamente através da segunda ferramenta, o HACCP. A utilização desta ferramenta permite estabelecer os limites críticos, um sistema de monitoramento e medidas de controle para todos os PCC. Desta forma, a qualidade destes produtos pode ser avaliada em tempo real, ou seja, durante o processo produtivo e antes da análise pelo controle de qualidade.

Resultado: Foi proposto e validado um fluxograma para o processo produtivo baseado em duas plataformas - a) plataforma procariótica (na qual são obtidos os plasmídeos que contem a informação genética dos produtos, concentrados e com alto grau de pureza através da transformação e cultivo de bactérias competentes) e b) plataforma eucariótica 
(na qual são obtidos os produtos com qualidade e pureza adequados através da transfecção e cultivo de células aderentes). A análise do processo produtivo identificou um total de 108 riscos (63 na plataforma procariótica e 45 na eucariótica) 72 riscos foram classificados como PCC. Destes, 40 se encontram na plataforma procariótica e 32 na eucariótica.

Conclusão: Aplicação das metodologias de análise de riscos a processos produtivos em transferência de tecnologia demonstrou ser bastante útil na medida em que identifica de forma prospectiva os riscos e propõe medidas de controle destes riscos antes do processo estar efetivamente implantado em Bio-Manguinhos o que permite agir de forma proativa e evitar não conformidades antes que estas ocorram. Além disso, estabelece uma base documental importante para elaboração dos Documentos Internos e de treinamentos. 